\author{
Blucher Proceedings \\ Cuba e Brasil no Século XXI (CBS21) \\ Inovação e Desenvolvimento Socioeconômico Sustentável
}

\title{
La Propiedad Industrial en Cuba en el Contexto Universitario.
}

Dra. Marta Moreno Cruz ${ }^{1}$ y Dra. Dánice Vázquez De Alvarée

La ciencia y las producciones de la ciencia, deben ocupar algún día el primer lugar de la economía nacional. Pero partiendo de los escasos recursos, sobre todo de los recursos energéticos que tenemos en nuestro país, tenemos que desarrollar las producciones de la inteligencia, y ese es nuestro lugar en el mundo, no habrá otro; todas estas que se derivan del esfuerzo que estamos haciendo en las investigaciones y en los productos de las investigaciones, porque en eso podemos competir con japoneses, alemanes y todos, con quienes sean.

Fidel Castro "Inauguración del Centro de Biofísica Médica de la Universidad de Oriente" (10 de febrero de 1993)

\section{Generalidades}

La Propiedad Intelectual en sus dos acepciones fundamentales, el Derecho de Autor y la Propiedad Industrial, es reconocida y regulada en Cuba. Desde el año 1975 nuestro país es miembro de la Organización Mundial de la Propiedad Intelectual como organismo especializado de la Naciones Unidas y somos parte de los Convenios fundamentales en esta materia, el Convenio de París de 1883 desde 1904 y el Convenio de Berna de 1886 desde suscrito en el año 1997.

En materia de Derecho de Autor está vigente la ley 14 del año 1977. Según el artículo 2 de esta norma se protegen por esta vía las obras científicas, artísticas, literarias y educacionales de carácter original, que se hayan hecho o puedan hacerse de conocimiento público por cualquier medio lícito, cualesquiera que sean

\footnotetext{
${ }^{1}$ Profesora Titular. Facultad de Derecho de la Universidad de La Habana (UH). Jefa de la Cátedra de Propiedad Intelectual de la UH. La Habana, Cuba. E-mail: marta.moreno@lex.uh.cu.

${ }^{2}$ Universidad de La Habana (UH), Cuba.
} 
sus formas de expresión, su contenido, valor o destino. En especial en el Artículo 7 establece como catálogo abierto un grupo de obras originales, entre ellas las obras escritas y orales, las obras musicales, las coreográficas y las pantomimas, las dramáticas y dramático musicales, las cinematográficas, las televisas y audiovisuales, las radiofónicas, las de dibujo, pintura, arquitectura, escultura, grabado, las fotográficas, las de arte aplicado y los mapas y planos. En el artículo 8 de la propia ley dispone la protección de obras derivadas tales como las traducciones, versiones, adaptaciones, arreglos musicales, las antologías, enciclopedias y otras compilaciones que, por la selección o la disposición de las materias, constituyan creaciones independientes.

La ley reconoce en su Artículo 4 de forma conjunta las facultades morales y patrimoniales que corresponden a los creadores. En el orden moral dispone el reconocimiento del derecho a la paternidad y la defensa de la integridad, oponiéndose a cualquier deformación, mutilación o modificación que se realice en la obra sin su consentimiento. En relación con las facultades patrimoniales establece el Derecho de Autor a realizar o autorizar la publicación, reproducción o la comunicación de su obra al público por cualquier medio lícito, bajo su propio nombre, bajo seudónimo o anónimamente y el derecho a realizar o autorizar la traducción, la adaptación, el arreglo o cualquier otra transformación de la obra, o sea la creación de obras derivadas. De forma especial regula que el autor recibirá una remuneración en virtud del trabajo intelectual realizado cuando su obra se utilice por otras personas naturales o jurídicas.

La duración de las facultades patrimoniales es de toda la vida del autor y cincuenta años post mortem en correspondencia con lo dispuesto en la Convención de Berna de la cual somos parte.

No somos miembros de la Convención de Roma y en este sentido no concedemos una protección por esta vía a los intérpretes, artistas, ejecutantes, productores de fonogramas y organismos de radiodifusión.

La protección nace con la creación, no obstante existe el Centro Nacional de Derecho de Autor, subordinado al Ministerio de Cultura, en el cual se registran las creaciones protegidas por esta vía, sin embargo como ya destacamos, dicho registro constituye un medio probatorio más y no es constitutivo de ningún derecho.

Si bien no se dispone en la norma de referencia de forma especial la protección de los programas de ordenador por esta vía, son protegibles a través del derecho de autor. Es de destacar que el objetivo básico del Derecho de Autor en el país es incentivar la creación, a través de una apropiada protección y reconocimiento a los autores, sin menoscabar el acceso a la cultura, la educación y el conocimiento, la difusión de nuestras obras y la defensa del patrimonio cultural y científico de la nación.

A diferencia del Derecho de Autor, la Propiedad Industrial en Cuba si ha sido 
objeto de modificaciones sustanciales en el orden normativo, a partir de ser miembros fundadores de la Organización Mundial del Comercio como continuadores del Acuerdo General de Aranceles y Comercio (GATT) de 1947 y suscribir el Acuerdo de los Derechos de Propiedad Intelectual relacionados con el Comercio (ADPIC). Desde el propio año 1995 se promulgó el Decreto- Ley 160, a los efectos permitir la presentación de solicitudes de patentes para los productos farmacéuticos y químicos para la agricultura, para cumplimentar lo dispuesto en el Artículo 70.8 del ADPIC. A partir de esta fecha se han promulgado nuevas disposiciones en materia de signos distintivos, indicaciones geográficas, invenciones, modelos de utilidad, modelos industriales, variedades vegetales y topografía de circuitos integrados.

Anteriormente en nuestro país se encontraba vigente el Decreto-Ley 68 del año 1983 que integraba de forma codificada la regulación de las diferentes modalidades de la Propiedad Industrial: descubrimientos científicos, invenciones, marcas, nombres comerciales, rótulos de establecimientos, indicaciones geográficas, lemas comerciales y modelos industriales. Esta normativa ha sido modificada casi íntegramente por las normativas que evaluaremos en el presente trabajo, solo están vigentes dos artículos relacionados con las cláusulas restrictivas que no deben ser incorporadas a los contratos de transferencia de tecnología.

De forma general la legislación vigente protege las creaciones intelectuales y garantiza el justo equilibrio entre los derechos concedidos y los objetivos fundamentales de política pública que constituyen intereses supremos del Estado cubano.

En nuestro país existe la Oficina Cubana de Propiedad Industrial (OCPI), perteneciente al Ministerio de Ciencia Tecnología y Medio Ambiente, la cual constituye la entidad que confiere y registra los derechos de Propiedad Industrial en sus diferentes modalidades.

De suma importancia resulta la norma promulgada en virtud de la Resolución 21 del 2002 del Ministerio de Ciencia Tecnología y Medio Ambiente que puso en vigor el Sistema Nacional de Propiedad Industrial, definiendo sus objetivos generales, así como los lineamientos metodológicos para el diseño y la organización de los sistemas internos de Propiedad Industrial en los órganos, organismos, empresas, instituciones y el sector cooperativo del país.

\section{Protección de las Invenciones y Dibujos y Modelos Industriales}

El 1 de abril de 2012 entra en vigor en Cuba el Decreto- Ley 290 en materia de Invenciones y Dibujos y Modelos Industriales el cual se aviene a los requerimientos de los ADPIC, haciendo gala de las flexibilidades en cuanto a objetos protegibles y además se despoja de instituciones históricas, poco atractivas para solicitantes extranjeros como el Certificado de Autor de Invención el cual reconocía la titularidad de las invenciones al Estado en determinados supuestos contemplados en la 
legislación anterior. Integra en su texto la protección de las Invenciones, Dibujos y Modelos Industriales y además a los Modelos de Utilidad. Sin embargo aún no se ha puesto en vigor el Reglamento que complementa este importante Decreto-Ley.

Con el Decreto-Ley 290, se implementan una serie de cambios no solo en cuanto a modalidades a proteger, sino también en cuanto a forma de protección, vigencia, naturaleza y alcance de los derechos exclusivos, límites a dichos derechos e inversión de la carga de la prueba.

Faltaría a nuestro juicio, revisar aspectos de suprema importancia, como son la observancia de los derechos y las modificaciones que necesariamente se requieren hacer a la Ley de Procedimiento Civil Administrativo Laboral y Económico (LPCALE).

\section{Aspectos Novedosos del Decreto Ley 290}

\section{Objetos de protección}

En el nuevo texto legal se incorpora la regulación de los modelos de utilidad, modalidad que no se encontraba regulada en nuestro país, protegiendo además como ya expusimos a las invenciones y los dibujos y modelos industriales.

La norma de referencia no recoge a los descubrimientos científicos, cuestión que consideramos atinada, toda vez que esta es una ley para la protección de las invenciones y los descubrimientos constituyen hallazgos de fenómenos o leyes existentes en la naturaleza, por lo que no deben establecerse monopolios o exclusividades sobre los mismos ${ }^{3}$.

\section{Titularidad}

El elemento más trascendente que incorpora el Decreto- Ley en este sentido es la eliminación del Certificado de Autor regulado en el Decreto- Ley 68 de 1983. Este certificado concedía la titularidad al Estado de todas las creaciones obtenidas en el marco de una relación de empleo, así como para determinados objetos de invención reconocidos en el artículo 39 del citado Decreto Ley. No tenía período de vigencia determinado, ni caducaba y no era necesario el pago de tasas para su adquisición y mantenimiento en vigor.

A partir del Decreto- Ley 290 los títulos de protección reconocidos (certificado de patente y certificado de registro), el primero para las invenciones y el segundo

\footnotetext{
${ }^{3}$ Los descubrimientos científicos se encontraban regulados en el Decreto-Ley 68 . Según esta disposición solamente se otorgaba un reconocimiento, lo cual era competencia de la Academia de Ciencias y no de la Oficina Cubana de Propiedad Industrial, quien fungía bajo el Decreto-Ley 68 como mero tramitador, era la Academia de Ciencias quien dictaminaba si se consideraba o no descubrimiento y la oficina concedía tal reconocimiento.
} 
para los modelos de utilidad y los dibujos y modelos industriales, definen la titularidad para las personas naturales y jurídicas pero no al Estado.

Lo anterior constituye un elemento que estimulará a las personas naturales y jurídicas extranjeras a solicitar patentes en Cuba en los sectores tecnológicos reconocidos en el Decreto Ley, toda vez que los derechos no se le reconocen al Estado cubano, sino a los titulares. Ello de hecho supondrá la existencia de derechos exclusivos en determinadas áreas que serán excluidas de utilización por parte de las empresas cubanas, excepto que cuenten con la autorización correspondiente por parte de los titulares de los derechos.

Por otra parte la eliminación del Certificado de Autor también teóricamente posibilitará la concertación de contratos de transferencia tecnológica, en especial licencias de patente, entre entidades de la economía nacional, incluyendo los centros de investigación científica y las universidades que podrán licenciar sus bienes intangibles a cambio de las remuneraciones correspondientes con el sector empresarial, lo cual les permitirá obtener fuentes de financiamiento para las actividades de investigación y desarrollo.

\section{El caso de una relación jurídico - laboral}

Al suprimirse el Certificado de Autor el Decreto Ley 290 incorpora la "Titularidad en ocasión de relación jurídico-laboral", aunque sin llegar a definir las invenciones laborales, bien por encargo, bien de servicios como teóricamente se reconocen y se definen en los diferentes textos normativos sobre esta materia.

Primero es conveniente tener claro que autor o inventor, no implica que obligatoriamente sea el solicitante de protección o futuro titular del derecho, siendo siempre conservado el derecho de paternidad sobre la invención a su autor o creador.

Es aconsejable entonces definir a las invenciones laborales como aquellas que se llevan a cabo en el marco de una empresa o con la efectiva colaboración o recursos de ésta.

Puede tratarse de una invención laboral de servicio (recogida en el derogado Decreto Ley 68 en el artículo 75) que es aquella que se obtiene en el marco de una empresa pero producto de un contrato laboral cuyo objeto es investigar. En este caso, la titularidad es del empresario. Algunas legislaciones ${ }^{4}$ establecen de

\footnotetext{
${ }^{4}$ Artículo 15.2 Ley Española de Patentes Ley 11/86. También Artículo 15 Ley 354 de 19/9/00 de Nicaragua, modificada por Ley 579 de 22/3/06 "ARTíCULO 15. Invenciones efectuadas en ejecución de un contrato. Cuando la invención haya sido realizada en cumplimiento o ejecución de un contrato de obra o servicio, o de un contrato de trabajo, el derecho a la patente pertenecerá a la persona que contrató la obra o el servicio, o al empleador, según corresponda, salvo disposición contractual en contrario. En el caso que la invención tenga un valor económico mucho mayor que el que las partes podían haber previsto razonablemente al tiempo de concluir el contrato, el inventor tendrá derecho a una remuneración proporcional que será fijada por la autoridad judicial competente en defecto de
} 
forma excepcional una retribución económica adicional cuando la investigación es relevante o excede de manera evidente del contenido o relación de trabajo.

O puede tratarse de una invención laboral de empresa cuando se realiza en el marco de la empresa pero no es contenido de trabajo del investigador-autor. En el resultado de la invención tienen que haber influido los conocimientos adquiridos dentro de la empresa o el uso de medios proporcionados por ésta.

En este caso el empresario tiene derecho a asumir la titularidad o reservarse un derecho de utilización pero el inventor, tiene derecho a una compensación económica justa ${ }^{5}$.

Todo parece indicar que el nuevo texto legal, recoge las invenciones laborales de servicio en su artículo 11.1 a) y las invenciones laborales de empresa en los incisos b) y c) del mismo artículo del Decreto Ley 290.

La participación de los autores e inventores en los beneficios que se obtengan por la explotación de la creación se reconoce en el artículo 11.3 del Decreto Ley y su instrumentación, se realizará a través de disposiciones complementarias dictadas por parte de los organismos competentes.

Por su parte, las Invenciones Libres son aquellas logradas por una persona de manera autónoma, sin apoyo de la entidad. La titularidad será siempre del trabajador.

Encontramos un peculiar artículo 9.1 del Decreto Ley de referencia que dispone la posibilidad de los solicitantes o titulares de patentes de conceder licencias, pero expresamente se define que dichas licencias tendrán carácter exclusivo, salvo pacto en contrario. Consideramos que tal prescripción no se aviene a la doctrina internacional y nacional sobre la materia y especialmente sobre las tendencias normativas actuales sobre la contratación económica en Cuba. Por otra parte, no encontramos el fundamento de tal disposición; la exclusividad o no de los contratos de transferencia de tecnología debe negociarse en todo el proceso de contratación y de no llegarse a un acuerdo, deberá disponerse la no exclusividad para evitar los abusos en el ejercicio de los derechos de Propiedad Industrial y propiciar una competencia leal ${ }^{6}$.

\section{Derecho de Prioridad}

acuerdo entre las partes".

${ }^{5}$ Así lo establece por ejemplo el artículo 17 de la Ley Española de Patentes (LEP). Existen legislaciones que establecen plazo para que el trabajador ponga en conocimiento de su empleador la invención (Ejemplo: 3 meses LEP) so pena de la pérdida de los derechos que se le reconocen al trabajador.

${ }^{6}$ Conocemos que Cuba es esencialmente un país importador de tecnologías, por lo que nos convendría la concesión de licencias exclusivas, es decir que entidades nacionales sean las únicas en explotar dichas tecnologías en nuestro territorio, pero ello debe ser logrado en el proceso de concertación de los contratos y no definir un precepto legal que pudiese ser incongruente con la normativa en materia de contratación económica en el país. 
El nuevo texto legal incorpora detalladamente la regulación del derecho de prioridad convencional ${ }^{7}$, en ocasiones, con redacción idéntica a la establecida por el Convenio de la Unión de París de 1883.

La prioridad de exposición también quedó regulada, siendo la técnica del artículo 19 mucho mejor y más ventajosa que la que estableció el artículo 51 del extinto Decreto Ley 68 cubano.

\section{Materia patentable}

Quedó establecido en el artículo 21.2 las invenciones solo para productos y procedimientos quedando de forma expresa y detallada, cada una de las creaciones que no se considerarán invenciones, manteniendo las establecidas por el extinto Decreto- Ley 68 e incorporando otras como por ejemplo: los esquemas de trazado de circuitos integrados; los programas de computación, las obras científicas, artísticas y literarias y las creaciones estéticas. En cuanto a las creaciones que no serán patentables, se establecen igualmente con detalle y se mantienen algunas que ya habían sido reguladas por el Decreto Ley 68.

A la hora de regular la materia patentable el legislador tuvo en consideración las flexibilidades establecidas en el artículo 27 del Acuerdo ADPIC de la OMC, toda vez que este artículo amplía de forma sustancial los objetos de invención que obligatoriamente deben ser protegidos por la vía de las patentes en las legislaciones domésticas de los estados miembros de esta organización.

\section{Requisitos de patentabilidad}

Quedaron reguladas en los artículos 23 al 25 la novedad, la actividad inventiva y la aplicabilidad industrial. En cuanto a la novedad, nuestra legislación sigue al criterio de novedad absoluta y aunque a nuestro juicio el artículo 40 del Decreto Ley 68 definía mejor la novedad, muy bien incorpora el nuevo texto la definición del estado de la técnica.

Se establece como excepción a este requisito de la novedad mundial lo definido en el artículo 19 relativo a la prioridad de exposición, la cual se amplía en relación con lo regulado en el Decreto Ley 68. Asimismo el artículo 23.4 del Decreto Ley 290 establece como divulgación inocua que no interfiere la novedad mundial, aquella que se produzca a partir de un acto ilícito contra el solicitante o titular, tal como aparece en muchas legislaciones de América Latina.

La actividad inventiva, sin embargo, a nuestro juicio en su actual redacción ofrece un mejor entendimiento que el antiguo artículo 41 del Decreto Ley 68.

\footnotetext{
${ }^{7}$ Este principio quedó establecido en el artículo 4 del Convenio de París, en su texto original de en 1883. La extensión del derecho de prioridad a los modelos de utilidad y a los causahabientes del primer solicitante fue introducida por la conferencia de revisión de Washington en 1911.
} 


\section{Procedimiento de concesión}

El capítulo II y el procedimiento para el registro de invenciones es completamente nuevo al amparo del Decreto- Ley 290.

La presentación de la solicitud mediante el formulario establecido por la OCPI debe acompañarse de todos los documentos establecidos en el artículo 26.1; resumen, descripción, reivindicación (es), dibujos, poder de representación en su caso, la acreditación del depósito del material biológico y la copia certificada de los documentos de reivindicación de prioridad, ya sea convencional o de exposición, previo pago de la tasa establecida, contando el solicitante con tres (3) meses para presentar el documento que acredite la reivindicación de la prioridad so pena de no tenerse en cuenta la fecha de prioridad reivindicada, tal como lo estableció el artículo 28.1 y en el caso de los documentos relativos al material biológico, el término dispuesto por el artículo 28.2 es de dieciséis (16) meses contados desde la fecha de presentación o de prioridad en caso de que se reivindique.

En relación con la descripción de la invención se dispone como cuestión importante en el inciso c del artículo 26.1 que el solicitante deberá indicar la mejor manera de llevar a efecto dicha invención. Cuestión novedosa e importante que ha incluido el legislador en el artículo 29 es la referencia al "único concepto inventivo"y a la "unidad de invención", sin embargo, es recomendable que se definan en el Reglamento.

Realizado el examen formal de la solicitud relativo al análisis de la documentación, la verificación del pago de la tasa, según el artículo 31.1, se notifica al solicitante de la existencia de alguna irregularidad, dándose la posibilidad de que ésta sea subsanada en sesenta (60) días contados desde la notificación del Requerimiento Oficial, prorrogables por treinta (30) días, según establece el artículo 32.1 y superadas las omisiones en la solicitud, se publica ésta en dieciocho (18) meses contados desde la presentación o la prioridad, lo cual quedó establecido en el artículo 33. En el caso de que el requerimiento oficial no sea contestado, la solicitud será abandonada y si el motivo del requerimiento es la falta de unidad de invención, el examen continúa sobre la primera reivindicación independiente.

Esta formulación del artículo 32.2, en el caso del abandono por no respuesta al requerimiento oficial, "sin que deje derecho subsistente", nos hace interpretar que puede darse la posibilidad de presentar nuevamente una solicitud reivindicando prioridad, claro está, siempre que se cumplan los requisitos que establece el Convenio de la Unión de Paris para la protección de la Propiedad Industrial.

Muy importante y novedoso resulta la publicación de todas las solicitudes, en tanto, sólo se publicaban en Cuba las invenciones que eran concedidas o las solicitudes que se referían a productos farmacéuticos y productos químicos para la agricultura según el Decreto Ley 160 ya referido.

A la publicación, le sigue un período de sesenta (60) días, según el artículo 34.1, 
para la presentación de oposiciones, escritos que una vez trasladados al solicitante puede éste proceder a su contestación en sesenta (60) días contados desde la fecha de notificación, según el artículo 35.1.

Contestadas las oposiciones, o continuando de oficio la Oficina con el trámite, se realiza el examen sustantivo, sin que para el caso de las patentes de invención el legislador haya fijado plazo, a diferencia del caso de los modelos de utilidad, que previó el plazo de 12 meses, a contar a partir del vencimiento del término para las oposiciones, donde la Oficina dictamina fundamentalmente, sobre las exigencias establecidas en el texto legal y sobre los documentos presentados en las oposiciones.

El examen de fondo otorga la posibilidad al solicitante de que pueda hacer subsanaciones, según el artículo 36.3, a lo cual sigue un primer pronunciamiento que deja la decisión al Jefe de departamento de Invenciones, según establece el artículo 39, mediante Resolución, en treinta (30) días desde que concluye el examen sustantivo, sólo que no se fijó el plazo en el cual debe realizarse ese examen sustantivo ${ }^{8}$.

Es novedosa la posibilidad que se otorga al solicitante de que pueda presentar comentarios sobre cualquier información o documento en cualquier etapa del examen, claro está, pagando la tasa de pago por documentos adicionales.

El hecho de que no se haya fijado plazo para la realización del examen sustantivo hace que exista un período de expectación para el solicitante que es sorprendido por una Resolución que puede o no conceder la solicitud y que es dictada en treinta (30) días por el Jefe del Departamento de Invenciones, según se estableció en el artículo 39, sin que quedara establecido en el Decreto Ley el término a partir del cual se cuentan los 30 días antes mencionados.

Una vez que es notificada a las partes la Resolución, si estuviera alguna parte inconforme, puede presentar Recurso de Alzada en treinta (30) días ante el Director General de la Oficina, quien, según se interpreta del artículo 41.1., contará con un plazo treinta (30) días para dictar Resolución, con la cual se agota la vía administrativa.

Se incorpora la posibilidad de una conciliación previa a la Resolución del Director General, en tanto el artículo 41.2 estableció la posibilidad de la invitación por la Oficina de las partes a conciliar, sin embargo, a nuestro juicio, habrá que esperar las precisiones del Reglamento sobre esta conciliación.

En caso de que no se hubiese presentado Recurso de Alzada, la Oficina dicta Resolución, establece el texto legal que "ratificando o no"lo dispuesto por el Jefe del Departamento de Invenciones, sin embargo, en la práctica sería difícil encontrar que sin que medie Recurso de Alzada la decisión sea diferente a la contenida en la

\footnotetext{
${ }^{8}$ Conocemos que es una práctica internacional, no regular un plazo para el examen sustantivo, sin embargo, no encontramos lógico que se imponga un plazo a un acto administrativo posterior a otro que no cuenta con plazo previamente establecido.
} 
primera Resolución.

$\mathrm{Si}$ el caso fuese que la solicitud es concedida, el solicitante cuenta con treinta (30) días a partir de la notificación de la Resolución para el pago de la tarifa correspondiente, según establece el artículo 41.3, expidiendo el Certificado la Oficina e inscribiendo y publicando la patente.

Tanto la publicación como el resto del procedimiento son nuevos en nuestro país, pues al amparo del antiguo Decreto Ley 68 no existía procedimiento de oposición ni tampoco posibilidad de recurso en vía administrativa.

Llama la atención que en una reglamentación tan extensiva y precisa del procedimiento de concesión como la definida en la norma que nos ocupa, no se haya incorporado la posibilidad de las observaciones de terceros, que difiere de las oposiciones y que se incorpora en diferentes legislaciones nacionales sobre esta materia.

\section{Vigencia}

Se prevé, a diferencia del Decreto- Ley 68 que establecía una duración de diez (10) años prorrogables a cinco (5) años, una duración del registro de 20 años, contados desde la presentación de la solicitud, quedando en este aspecto el artículo 42 de nuestra legislación en correspondencia con las exigencias del artículo 33 del ADPIC.

\section{Alcance de los derechos}

Quedó establecido en el artículo 44 que los derechos se ejercen desde la concesión, dejando claramente establecido el artículo 45 que no existe protección provisional en Cuba. Esto significa que los derechos de patente no se pueden hacer valer por el titular frente a terceros que hubiesen llevado a cabo un acto de explotación de la invención entre la fecha de publicación de la solicitud y la fecha de concesión de la patente.

El artículo 46 formula el derecho exclusivo como un derecho negativo, de impedir que terceros realicen los actos previstos en el texto legal.

Es muy avanzado en alcance de derechos exclusivos el nuevo texto legal en relación con el extinto Decreto- Ley 68 el cual no definía claramente el contenido de dichos derechos exclusivos y no incluía expresamente a la importación como uno de esos derechos.

Se distingue en el artículo 46 el alcance de los derechos cuando la materia de la patente sea un producto o un procedimiento. Cuando se trata de un procedimiento incorpora la protección indirecta, o sea los derechos exclusivos se extienden al producto resultante de dicho procedimiento, reforzando los derechos exclusivos del titular de dicha patente de procedimiento.

Cuando el producto obtenido por un procedimiento patentado es nuevo se presume, salvo prueba en contrario, que todo producto idéntico producido sin el 
consentimiento del titular de la patente de procedimiento ha sido obtenido por el procedimiento patentado. Corresponde al demandado, según el artículo 143.1 del Decreto Ley 290 probar que el procedimiento para obtener el producto es diferente al procedimiento patentado, lo que se conoce como inversión de la carga de la prueba.

\section{Límites al ejercicio de los derechos de patentes}

En materia de límites, también cuenta el nuevo texto legal en el artículo 47 y siguientes, con mejores fórmulas a la del artículo 54 del Decreto- Ley 68, e incorpora actos como aquellos destinados a una futura explotación comercial con posterioridad a la expiración de la patente.

El principio del agotamiento del derecho, devenido de la jurisprudencia alemana y posteriormente extendido a Europa, opera como un límite al derecho exclusivo del titular del registro.

La doctrina distingue tres tipos de agotamiento: nacional, comunitario e internacional. En el artículo 48 quedó establecido el agotamiento internacional. Este tipo de agotamiento tiene ciertas ventajas si tenemos en cuenta que ello estimula la competencia y evita que los mercados se enmarquen y por tanto se restrinja el comercio, eliminando un posible monopolio sobre los precios de los productos.

También incorpora otros límites importantes al derecho de patentes como la disposición bolar reconocida en el inciso g) del artículo 47 al establecer que el derecho de la patente no se extiende a los actos realizados con fines de experimentación, procesamiento, tramitación o cualesquiera otras finalidades destinadas a obtener el registro u otras formas de autorización sanitaria y a preparar una futura explotación comercial a la expiración de la patente y el derecho del usuario anterior regulado en el artículo 49 del Decreto Ley de referencia.

\section{Otros usos sin la autorización del titular de la patente}

Algunos de los artículos del Decreto- Ley 290 en esta materia son idénticos a la regulación del ADPIC, otros amplían los del extinto Decreto- Ley 68.

Consideramos de suma importancia la precisión en la norma de todas las disposiciones en materia de licencias obligatorias, toda vez que el uso debido de esta institución en el Derecho de patentes constituye un instrumento vital para evitar el abuso de los derechos de Propiedad Industrial y garantizar el equilibrio entre los intereses sociales y los de los titulares de las patentes.

Sería cuestionable la aplicación del inciso g del artículo 53.1 del Decreto Ley 290, que establece como uno de los supuestos para la concesión de las licencias obligatorias todo acto que constituya un ejercicio abusivo de los derechos conferidos y toda práctica que, a resultas de un proceso judicial o administrativo se haya determinado que es anticompetitiva, toda vez que no existe en nuestro país una re- 
gulación en materia de competencia, ni están establecidos órganos que determinen este tipo de prácticas.

\section{Renuncia, nulidad, caducidad y cancelación de la patente}

Las figuras de renuncia, nulidad, cancelación y caducidad quedaron establecidas de forma independiente, a nuestro juicio en un no buen empleo de la técnica, en tanto la cancelación como figura no es causa de extinción del derecho y si una consecuencia de dicha extinción. Ello quiere decir, que la caducidad y la nulidad deben tener como efecto una cancelación.

Así el Capítulo IV enuncia los supuestos por los cuales se puede solicitar la nulidad, la renuncia, la caducidad y la cancelación.

\section{Restablecimiento de derechos}

Se incorpora al texto legal el restablecimiento de derechos, cuestión que hasta el momento dejaba en estado de indefensión al solicitante en determinadas circunstancias. Aunque el artículo 124 a nuestro juicio tiene una redacción poco clara, los plazos establecidos en el artículo 123 son bien claros y esta acción debe ser ejercida en sesenta (60) días a partir de que cesa el impedimento.

\section{Infracción de derechos}

Desde el punto de vista jurídico, el Decreto- Ley 290 resulta acertado toda vez que establece numerosas acciones como medidas cautelares y también como medidas definitivas de fondo, pudiendo actuar el titular del derecho y también el licenciatario.

Las acciones por infracción de derechos se establecerán en vía judicial ante la sala competente del Tribunal Provincial de La Habana.

\section{Medidas cautelares}

Las medidas cautelares pueden ser solicitadas antes, conjuntamente o con posterioridad a la acción, siendo posible que el Tribunal disponga como medidas provisionales: el cese inmediato de los actos de infracción, el embargo o retención de los productos y la prohibición de la importación o exportación.

En cuanto a la ejecución, si se establece antes de la presentación de la demanda, queda sin efecto si no se presenta la demanda en treinta (30) días hábiles desde la fecha de ejecución de la medida.

\section{Medidas en frontera}

Por último y de forma muy novedosa, el Decreto-Ley 290 incorpora la regulación de medidas en frontera en los artículos 146 y siguientes, dando la posibilidad a la Aduana de actuar, de oficio o por orden del Tribunal Provincial Popular que 
corresponda, lo que se traduce en la retención cuando se supone la preparación de una importación / exportación que infringe derechos de Propiedad Industrial.

Si bien el derogado Decreto-Ley 68 no dedicaba ningún acápite a las medidas en frontera, la ejecución de éstas por la Aduana estaba regulada en la hoy derogada Resolución 21 de 1997 "Normas para la retención de mercancías por infracción de los derechos de Propiedad Intelectual" que establecía un procedimiento mediante el cual la Aduana sólo actuaba a instancia de parte permitiendo la retención por diez (10) días.

En Septiembre del 2001 se firmó la Resolución 25/2001 por el Jefe de la Aduana General de la República, que deroga la Resolución 21/97 y que de forma novedosa establece el procedimiento para la ejecución de retenciones por la Aduana como órgano ejecutor, pudiendo la misma actuar a instancia de parte, a instancia de autoridad administrativa o judicial competente o de oficio. Sin embargo, en la práctica, la aduana ejecutará medidas en frontera por orden del tribunal competente.

\section{La Protección de los Modelos de Utilidad y la Protección de los Dibujos y Modelos Industriales}

La incorporación de los modelos de utilidad es algo totalmente novedoso, en tanto, en nuestra legislación no se reconocía la protección de tal modalidad.

Quedó definido en el artículo 74 cuáles modelos de utilidad son protegibles en Cuba, quedando recogido de forma diferente a otras legislaciones pues es regulado de forma equiparable a una Invención, siendo exigibles los requisitos de patentabilidad previstos en el texto legal.

Se diferencian los modelos de utilidad de las invenciones, según la norma cubana de referencia en tres aspectos fundamentalmente: en el período de vigencia, que es menor, diez (10) años en el caso de los modelos de utilidad y veinte (20) años en las invenciones; en el procedimiento de concesión, y en el nombre que adopta la forma de protección, Certificado de patente en las invenciones y de Registro en los modelos de utilidad. Asimismo, no pueden registrarse como modelos de utilidad los procedimientos y los productos químicos y biotecnológicos. El análisis de los requisitos de patentabilidad tiene el mismo rigor tanto en los modelos de utilidad como en las invenciones.

En las legislaciones nacionales y en la doctrina, los modelos de utilidad tienen ciertas particularidades en relación con las invenciones, lo cual no ha sido reconocido tal cual en nuestra nueva legislación sobre esta materia ${ }^{9}$. Generalmente si

\footnotetext{
${ }^{9}$ En la práctica internacional existe diversidad en la regulación de esta figura, algunas exigen actividad inventiva alta y novedad local; otras, actividad inventiva restringida y novedad mundial; de igual manera la gran mayoría de las legislaciones no protegen los procedimientos.
} 
consisten como lo establece el artículo 74.2 del Decreto Ley 290 en una configuración, estructura o constitución de un producto o de sus partes, de la que resulte alguna mejoría funcional para su utilización, pero se es más flexible en el análisis de la actividad inventiva y en ocasiones la exigencia de la novedad es local y no mundial, todo lo cual hace la diferencia con la legislación cubana.

El contenido de la regulación de esta nueva modalidad en nuestra legislación obedece al principio de ser rigurosos en la concesión de derechos exclusivos sobre nuevas creaciones y no constituir monopolios en aquellos casos donde ciertamente la innovación tenga un nivel inventivo que no amerite el otorgamiento de exclusividades, que imposibiliten la utilización libre de las mismas por parte de terceros.

No obstante creemos que es otra opción que tienen las empresas a la hora de definir qué forma de protección adoptar para sus innovaciones tecnológicas.

En cuanto a los Dibujos y Modelos Industriales, la definición del artículo 91 supera la del artículo 108 del Decreto Ley 68 que aunque protegía las formas bi y tridimensionales no contenía buena técnica en la redacción. Distingue y conceptualiza de forma expresa tanto el dibujo como el modelo industrial.

Establece como uno de los requisitos para su protección la novedad. No menciona que sea mundial, aunque de un análisis general de las regulaciones de esta modalidad contenidas en el texto legal, se presume que tiene este carácter, sin embargo, consideramos que debió ser expresa tal mención.

Un aspecto superado en esta norma es el requisito de progresividad establecido en el Decreto-Ley 68 para los modelos industriales que constituía un error y conllevaba a confusión entre esta modalidad y los modelos de utilidad. Ciertamente es el elemento estético y formal novedoso lo que distingue a los diseños industriales, independientemente que este elemento influya en el funcionamiento del producto.

Se mantiene la vigencia de diez (10) años, aunque con el extinto Decreto Ley 68 para llegar a los diez (10) años de protección se requería tramitar la renovación a los 5 años de vigencia, pues el registro se otorgaba por cinco (5) años con la posibilidad de extenderlo a diez (10) años.

Se regula de forma correcta a nuestro juicio todo lo relacionado con los derechos conferidos por el registro y las principales limitaciones de los derechos de los titulares de esta modalidad. También hay una acertada regulación del procedimiento de concesión para la adquisición de la protección.

Es esta modalidad de suma importancia, y su uso ha sido relegado en la práctica empresarial cubana. Con la actualización de nuestro modelo de desarrollo económico y social se requiere una renovación integral de su uso, tanto por las personas naturales como jurídicas nacionales y extranjeras que operan en la economía nacional.

En materia de invenciones, modelos de utilidad y diseños industriales Cuba es signataria de los siguientes Tratados que se encuentran en vigor: 
1. Tratado de Cooperación en materia de Patentes desde el 16 de abril de 1996.

2. Tratado de Budapest sobre el Reconocimiento Internacional del Depósito de Microrganismos a los fines del procedimiento en materia de patentes desde el 19 de febrero de 1994.

3. Arreglo de Locarno sobre la Clasificación Internacional de Dibujos y Modelos Industriales desde el 19 de octubre de 1998.

4. Arreglo de Estrasburgo sobre la Clasificación Internacional de Patentes desde el 9 de noviembre de 1996.

En relación con las variedades vegetales nuestro país no es miembro del Convenio UPOV y adoptó, en correspondencia con lo establecido en el Artículo 27.3 del Acuerdo ADPIC conferirle una protección a esta modalidad que combine elementos del régimen de patentes y de la protección sui géneris que dispone el mencionado Convenio. A tales efectos desde noviembre del 2011 se promulgó el Decreto ley 291 "De Protección de las Variedades Vegetales" que de forma paulatina instrumentará la protección a los géneros y especies que taxativamente se determinen. Esta regulación se estableció teniendo en cuenta la importancia en el orden económico, en especial para el desarrollo agrícola sostenible, de la obtención de nuevas variedades vegetales, y por tanto la promulgación de un cuerpo legal independiente que dispense protección a dicha modalidad adecuado a la importancia del mejoramiento vegetal. También de forma especial en Cuba se encuentran protegidos los esquemas de trazado de circuitos integrados a partir de una normativa especial puesta en vigor a través del Decreto-Ley 292 de noviembre de 2011. Esta normativa se corresponde con las exigencias mínimas dispuestas en los artículos del 35 al 38 del Acuerdo ADPIC de la OMC.

\section{Protección de los Signos Distintivos}

En esta materia en Cuba está vigente desde el año 1999 el Decreto ley 203 "De Marcas y Otros Signos Distintivos", el cual derogó al Decreto-Ley 68 en lo relativo a estas modalidades de la Propiedad Industrial. Asimismo rige la Resolución número 63/2000 Reglamento del Decreto Ley número 203 de mayo del 2000. A continuación comentamos los aspectos más relevantes de estas normativas.

\section{Definición y tipos de marcas}

En cuanto a definición de marcas, la doctrina distingue la existencia de tres sistemas para enmarcar el concepto de marca: El Sistema del concepto general, que tiene como ventaja que no juzga los tipos de signos que pueden llegar a ser una marca pero con ello genera inseguridad jurídica, siendo ello su mayor desventaja; el Sistema que establece un catálogo cerrado de signos que pueden constituir 
una marca, que a diferencia del primer sistema tiene una gran dosis de seguridad jurídica pero es un sistema poco flexible y el Sistema Intermedio, que combina las ventajas de los dos sistemas anteriores.

El Decreto-Ley 203 define una marca como: "todo signo o combinación de signos, que sirva para distinguir productos o servicios de sus similares en el mercado" ${ }^{\prime \prime}$.

Con esta definición, el Decreto-Ley 203 se afilia - a nuestro juicio- al Sistema Intermedio, logrando con la combinación de sistemas uno óptimo, tal como fue creado por la Ley Española de Marcas Ley 32 de 10 de noviembre de $1988^{11}$.

En cuanto a los tipos de marcas, el texto legal deja establecido los signos que pueden constituir marcas permitiendo el registro no sólo a los signos denominativos, figurativos y mixtos sino también a las formas tridimensionales, dejando además la posibilidad de regular en el futuro las marcas sonoras y olfativas.

Con respecto a los signos que pueden constituir marcas el texto legal deja claro que pueden registrarse marcas denominativas, dentro de éstas las letras, palabras, cifras y combinaciones de signos; marcas figurativas y dentro de estas, imágenes, símbolos, dibujos, figuras, gráficos, combinaciones de colores y marcas mixtas.

\section{Nacimiento del derecho}

Existen tres sistemas que definen el nacimiento del derecho sobre la marca ${ }^{12}$.

El primer sistema es el del Uso, mediante el cual el derecho se adquiere por el uso del signo distintivo. Este sistema tuvo su origen en Francia a partir del silencio de la legislación que provocó que los tribunales dictaminaran que la marca pertenecía a quien primero la ocupara.

El segundo sistema es el de la Combinación del principio del registro con el del uso, mediante el cual los derechos sobre el signo distintivo se adquieren por el derecho sobre la marca registrada, otorgándose a los usuarios de marcas no registradas determinados derechos.

El tercer sistema que destaca la doctrina sobre el nacimiento del derecho es el de la Combinación del sistema de registro con el de notoriedad de la marca no registrada, en el cual el derecho pleno sobre la marca se adquiere con el registro sin embargo otorga protección al simple usuario siempre y cuando esta marca que ha sido usada, ha adquirido determinada notoriedad.

A nuestro juicio, el Decreto-Ley 203, en cuanto al nacimiento del Derecho también hace una combinación de Sistemas al afiliarse al Sistema de Registro con Notoriedad de la Marca no registrada, pues aunque en Cuba el derecho pleno se

\footnotetext{
${ }^{10}$ Decreto Ley 203 de 2 de mayo del 2000, artículo 2, GOE No. 3 Año XCVIII.

${ }^{11}$ Esta Ley fue sustituida por la Ley $17 / 2001$, de 7 de diciembre, de Marcas (publicada el BOE No. 294 de 8 de diciembre de 2001)

${ }^{12}$ TATO PLAZA, Derecho Español de Marcas, Magíster Lvcentinvs, 1998
} 
adquiere por el registro, se le reconoce al simple usuario ciertos derechos si la marca se considera notoria en el territorio.

Así, con esta afiliación al sistema de nacimiento del derecho, el texto legal cubano gana claridad y justicia dentro del sistema internacional de Propiedad Industrial y el problema no estaría en sí en la aplicación del sistema que combina el registro con la notoriedad de la marca no registrada sino en la apreciación subjetiva por parte de los examinadores de cuando es o no una marca notoria en Cuba.

Aunque la doctrina ha conceptualizado la marca notoria como aquella ampliamente conocida por los consumidores habituales del producto o servicio al que se aplica la marca y además ha dejado establecido los requisitos para considerar notoria una marca, esta apreciación subjetiva pudiera traer como consecuencia inseguridad jurídica. Recordemos el caso HARD ROCK CAFÉ cuya notoriedad no fue apreciada en vía administrativa ni en primera instancia en vía judicial, solamente apreciada por el Tribunal Supremo Popular de Cuba.

En la práctica la aplicación de este sistema resulta controvertida pues a la Oficina no le basta que el titular extra registral de una marca notoria pruebe su uso y difusión en el territorio sino también la inminente posibilidad de confusión en el consumidor con respecto a la marca registrada.

\section{Solicitantes}

A diferencia de lo establecido en el Decreto-Ley 68, el texto legal introduce una importante novedad en cuanto a la capacidad para solicitar registro de marcas.

De tal modo, otorga la posibilidad de solicitar el registro de marcas a personas naturales y jurídicas cubanas y extranjeras.

Sobre este particular, vale aclarar que el antiguo Decreto-Ley 68 no prohibía expresamente el registro de marcas a personas naturales cubanas pero si podemos afirmar que existía una prohibición tácita en tanto se establecía una obligación de registro para los Órganos de la Administración Central del Estado (OACE), Empresas, Instituciones y Órganos Locales del Poder Popular (OLPP). De hecho, hasta donde sabemos, nunca fue aceptada por la Oficina Cubana de la Propiedad Industrial una solicitud de registro de marcas a nombre de una persona natural cubana.

Esta situación viene a dar al traste con la autorización que en el año 1993 por Resolución Conjunta No. 1 CETSS $^{13}$ - CEF $^{14}$ de 8 de septiembre de 1993, se otorga al trabajo por Cuenta Propia, posteriormente regulada por la Resolución

\footnotetext{
${ }^{13}$ Comité Estatal de Trabajo y Seguridad Social, actualmente Ministerio de Trabajo y Seguridad Social.

${ }^{14}$ Comité Estatal de Finanzas, actualmente Ministerio de Finanzas y Precios.
} 
Conjunta 1/1996 MTSS $^{15}$ - MFP ${ }^{16}$, y actualmente la Resolución en vigor es la No. 09/2005 MTSS y 253/03 del $\mathrm{MFP}^{17}$. Al momento de realizarse la autorización a los cuentapropistas, éstos no contaban con una fórmula legal eficaz para distinguir sus productos o servicios del resto de sus similares.

Asimismo, deja claro que los solicitantes extranjeros tienen los mismos derechos y obligaciones que los nacionales, de acuerdo a los Tratados y Convenios de que Cuba forma parte, lo cual no estableció de forma expresa el Decreto Ley 68 con excepción del derecho de prioridad convencional y de exposición.

Con el actual texto legal, se abre la posibilidad de que las sucursales extranjeras acreditadas en Cuba comparezcan ante la Oficina Cubana de la Propiedad Industrial a través de su representante legal, un representante designado o un Agente Oficial acreditado. Con ello, se abre el diapasón de los que pueden actuar ante la OCPI toda vez que tradicionalmente sólo podían representar a las personas jurídicas bien un agente oficial acreditado o bien su representante acreditado ante la Oficina Cubana de Propiedad Industrial.

Por último como novedad define al agente oficial, no definido con anterioridad en la regulación marcaria y cuyos requisitos y procedimiento de autorización quedó regulado por la Resolución 2900 de 1995 de la Oficina Cubana de la Propiedad Industrial, la cual fue derogada por la Resolución 659 del $2002^{18}$ de la OCPI.

\section{Procedimiento de registro}

El procedimiento para el registro de marcas es completamente nuevo al amparo del Decreto-Ley 203.

La presentación de la solicitud mediante el formulario establecido por la OCPI debe acompañarse de las reproducciones del signo, Poder de Representación en su caso y la copia certificada de los documentos de reivindicación de prioridad, ya sea convencional o de exposición, previo pago de la tasa establecida, otorgándose al solicitante un plazo de 2 meses para presentar cualquier documento no acompañado con la solicitud, así como 3 meses para presentar el documento que acredite la reivindicación de la prioridad so pena de no tenerse en cuenta la fecha de prioridad reivindicada.

Realizado el examen formal de la solicitud relativo al análisis de la documentación, la verificación del pago de la tasa y el requisito de legitimación para la condición de solicitante, se notifica al solicitante de la existencia de alguna irregularidad, dándose la posibilidad de que ésta sea subsanada en 2 meses contados

\footnotetext{
${ }^{15}$ Ministerio de Trabajo y Seguridad Social.

${ }^{16}$ Ministerio de Finanzas y Precios.

${ }^{17}$ La actualización fue obtenida de la Sra. Emilia Suárez Magallón, especialista del MTSS.

${ }^{18}$ El Reglamento de Agentes Oficiales y Representantes de Propiedad Industrial, establecido por la Resolución No. 659 del 2002 está disponible en el sitio www.ocpi.cu, consultado el 18 de abril del 2008.
} 
desde la notificación del Requerimiento Oficial, prorrogable por 1 mes, y superadas las omisiones en la solicitud, se publica ésta en 6 meses contados desde la presentación o la prioridad.

A la publicación, le sigue un período de 2 meses para la presentación de observaciones u oposiciones, escritos que una vez trasladados al solicitante puede éste proceder a su contestación en 1 mes contado desde la fecha en que se le da traslado.

Contestadas las observaciones u oposiciones, o continuando de oficio la Oficina con el trámite, se realiza el Examen sustantivo antes de los 12 meses contados desde la presentación o fecha de prioridad, donde la Oficina dictamina sobre las prohibiciones absolutas, relativas y los documentos presentados sobre las observaciones y oposiciones.

Una vez vencidos los 12 meses, se dicta el pronunciamiento preliminar sobre la concesión o denegación total o parcial y resolviendo las observaciones y oposiciones mediante el Informe Conclusivo de Examen, emitido por el Director del Departamento de Marcas.

Una vez notificado al solicitante el informe conclusivo de examen, puede este en el plazo de 1 mes contado desde la notificación, interponer Recurso de Alzada en Vía Administrativa ante el Director de la Oficina Cubana de la Propiedad Industrial, previo pago de una tasa.

Este Recurso de Alzada es dentro del nuevo sistema de registro, uno de los aspectos más novedosos del procedimiento pues así queda establecido un recurso en vía administrativa que da al solicitante mayor seguridad jurídica, más aún si tenemos en cuenta que el solicitante sólo contaba con la posibilidad de interponer recurso administrativo en vía judicial.

Con posterioridad a ello se dicta la Resolución de Concesión o Denegación, la cual es notificada al solicitante.

Claro está que si el Informe Conclusivo de Examen declara la concesión del registro tal como fue solicitado, se dicta con posterioridad la Resolución de concesión, el solicitante debe pagar la tasa de concesión emitiendo la Oficina el correspondiente Certificado de Registro.

Tanto la publicación de la marca en estado de solicitud como el resto del procedimiento son nuevos pues al amparo del antiguo Decreto-Ley 68 la marca se publicaba ya concedida y no existían procedimientos de observación u oposición, ni tampoco posibilidad de recurso en vía administrativa.

Se establece el uso obligatorio de los Arreglos de Niza (15 de junio de 1957) y Viena (12 de junio de 1973) relativos a la Clasificación Internacional de Productos y Servicios y elementos figurativos respectivamente, para el registro de marcas.

A diferencia del antiguo Decreto-Ley 68, el vigente Decreto-Ley 203 establece el Sistema Multiclase para el registro de marcas. 
Este sistema ofrece al solicitante una gran ventaja económica pues mediante el pago de una tasa puede solicitar el registro de una marca cubriendo hasta tres clases del nomenclador internacional de productos y servicios.

Este sistema es la antítesis del que rigió con el Decreto-Ley 68 con el cual el solicitante sólo podía amparar con su solicitud el registro de la marca en una clase.

\section{Duración del registro}

Se prevé al igual que lo hizo el Decreto-Ley 68 la duración del registro por 10 años, renovables por igual período.

\section{Marcas notorias}

Un aspecto particularmente novedoso lo constituye el tratamiento a las marcas notorias, toda vez que el antiguo Decreto-Ley 68 al referirse a marca notoria lo hacía como marca comúnmente conocida, término a nuestro juicio impreciso y de poco rigor.

La marca notoria es definida por el Profesor FERNÁNDEZ NOVOA como aquella "marca que goza de difusión y ha logrado el reconocimiento de los círculos interesados (los consumidores y los competidores)" 19. Claro está una marca para que sea considerada notoria en un territorio requiere que se haya usado en el mismo y que goce de difusión.

El Decreto-Ley 203 amplía la protección a las marcas notorias de forma tal que queda prohibido el registro como marca de un signo que imite o reproduzca una marca notoria; asimismo, se le reserva al titular noventa días para que solicite el registro, contados a partir de la cancelación, nulidad o caducidad del registro, en aquellos casos en que la marca hubiera sido registrada de mala fe por un tercero.

\section{Restablecimiento de derechos}

Sobre el restablecimiento del derecho, tema omitido por el Decreto-Ley 68, el actual Decreto-Ley 203 da la posibilidad, previo pago de una tarifa y la exposición de los hechos y justificación del incumplimiento del plazo, de restablecer el derecho en dos meses desde el cese del impedimento y en el año siguiente a la expiración del plazo de incumplimiento.

\section{Derechos exclusivos}

El derecho exclusivo es tratado doctrinalmente en dos aspectos, el positivo que da la facultad de uso al titular del registro de marca y el negativo que da la facultad de prohibir a un tercero que sin el consentimiento del titular un tercero use un signo idéntico o similar a su marca registrada para productos o servicios idénticos o similares, conocido como ius prohibendi.

\footnotetext{
${ }^{19}$ FERNÁNDEZ-NOVOA, Derecho de Marcas, Editorial Marcial Pons, Madrid, 1990, p. 34.
} 
En el Decreto-Ley 203 se establece en principio la arista positiva del derecho exclusivo al declarar en su artículo 40 que "el registro de la marca confiere a su titular el derecho exclusivo de usarla en el tráfico económico" pero en su artículo 42 hace una enumeración expresa de los actos que el titular puede impedir que un tercero realice sin su consentimiento.

Asimismo deja establecidos los límites al derecho exclusivo al igual que lo hacen otras legislaciones y no autoriza al titular a que prohíba a un tercero el uso siempre que éste sea necesario para indicar destino, aplicación, compatibilidad, indicaciones de especie, cantidad, calidad, procedencia geográfica, un término descriptivo, en los casos de accesorios y piezas sueltas y en el caso que el nombre y dirección del tercero sea idéntico o semejante al de la marca registrada.

Evidentemente, el establecimiento de estas facultades positivas y negativas en el texto legislativo en materia de marcas (Decreto Ley 203) supone un importante paso de avance toda vez que el Decreto-Ley 68 no establecía el contenido de los derechos exclusivos.

\section{Agotamiento del derecho}

El principio del agotamiento del derecho, devenido de la jurisprudencia alemana y posteriormente extendido a Europa, opera como un límite al derecho exclusivo del titular del registro de marca.

La doctrina, al igual que en materia de invenciones distingue tres tipos de agotamiento: Nacional, Comunitario e Internacional.

Por su parte la legislación cubana que comentamos establece que "el registro de una marca no confiere a su titular el derecho de prohibir a un tercero el uso de la misma en relación con productos que, legítimamente marcados, hayan sido introducidos lícitamente en cualquier mercado con esa marca por él, o por otra persona con su consentimiento o económicamente vinculada a él, a condición de que los productos y los envases o embalajes que estuviesen en contacto inmediato con ellos no hubiesen sufrido ninguna modificación, alteración o deterioro, u otro motivo legítimo que justifique que el titular se oponga a la comercialización ulterior de los productos".

Tal como queda establecido el artículo 47.1 del Decreto Ley 203 se afilia a la doctrina del agotamiento internacional de derechos, contrastable ante el silencio del Decreto Ley 68 en relación con esa institución.

Claro está, el principio del agotamiento del derecho aunque se encuentra íntimamente ligado a la facultad positiva de uso, como afirma el Profesor FERNÁNDEZ NOVOA en su libro "Derecho de Marcas", y a la puesta en venta del producto, no operará nunca cuando se trate de fijar un precio de reventa a los distribuidores pues el titular sólo puede fijar el precio de venta. El agotamiento del derecho como limitación a los derechos exclusivos de los titulares tampoco opera cuando exista falsificación del producto, reventa fuera del sistema de distribución en los casos 
de aquellos productos que requieren asistencia especializada, cuando se lesionen la calidad y prestigio de la marca o se afecte el consumidor.

\section{Uso}

Contrasta el detallado tratamiento que da al uso de marcas el Decreto-Ley 203 si tomamos en cuenta que el Decreto-Ley 68 sólo establecía la obligatoriedad en tres años contados desde la concesión del registro.

Con el nuevo Decreto-Ley 203 quedan establecidas las condiciones del uso en espacio, tiempo, cantidad y modo.

Así, se considera uso cuando los productos o servicios que ampare la marca sean puestos en el comercio, por los canales de distribución, o se encuentren disponibles para el consumidor en el territorio nacional.

De la redacción de este artículo se desprende que la enumeración que hace el legislador es excluyente, o sea, puesta en el comercio por los canales de distribución y circuitos comerciales o disponibilidad para el consumidor de destino dentro del territorio nacional. Asimismo, se establece que esa puesta en el comercio debe realizarse de forma continua y en la cantidad y modo que corresponda de acuerdo a la dimensión del mercado, la naturaleza del producto o servicio y la modalidad bajo la cual se realiza la comercialización.

Más adelante establece otras formas que se consideran uso de la marca como lo son: su empleo en relación los productos destinados a la exportación desde el territorio nacional; el uso de forma que difiera en elementos no esenciales o que no alteren la identidad de la marca y el empleo en la publicidad en dos meses previo a la puesta del producto o servicio en el mercado.

Se establece la obligatoriedad de un uso efectivo y real en un plazo de tres años desde la fecha de concesión del registro. Este uso obligatorio, establecido en todas las legislaciones de Propiedad Industrial está basado en los principios generales de consolidación de la marca como bien inmaterial y aproximación de la realidad registral a la extra registral.

De igual forma, no existe una concreción de la obligatoriedad del uso por ejemplo en lo referido a una declaración de uso a los tres años de concedido el registro. Sólo se hace referencia a la admisión de prueba de uso por cualquiera de los medios de prueba admitidos en la legislación cubana como por ejemplo documental, testifical, pericial y confesión.

\section{Renuncia, nulidad, cancelaciòn y caducidad}

Las figuras de renuncia, nulidad, cancelación y caducidad quedaron establecidas de forma independiente, a nuestro juicio en un muy mal empleo de la técnica pues el Decreto-Ley 203 dejó establecidos determinados supuestos para la solicitud de cancelación de registros marcarios como por ejemplo cuando la marca haya 
sufrido un proceso de generalización convirtiéndose así en designación usual, configurándose la cancelación en la legislación cubana, como causa de extinción del derecho y no como una consecuencia de dicha extinción.

Así, el Capítulo V enuncia los supuestos por los cuales se puede solicitar la nulidad, la cancelación y la caducidad.

En cuanto a la renuncia, se establece una novedad en cuanto a la formalidad del escrito a presentar a la Oficina Cubana de la Propiedad Industrial, el cual debe ser protocolizado ante Notario Público Cubano.

\section{Modificaciones de derecho}

El principio de la inmutabilidad de la marca registrada se consagra a plenitud en el Decreto-Ley 203 toda vez que no son aceptadas las variaciones en la marca. Las variaciones que sufran las denominaciones o el diseño dentro de una etiqueta de una marca, no serán aceptadas por el registro, por lo cual una nueva solicitud debe ser presentada para obtener la protección.

En lo que se refiere a las modificaciones en la persona del titular, a saber un traspaso, fusión o un cambio de nombre, el texto legal establece que deben ser inscritas en la Oficina. Asimismo, son aceptados los cambios de dirección.

El principio de indivisibilidad de la marca es consagrado desde tiempos remotos. El texto legal cubano acepta el traspaso parcial de los productos o servicios que ampara la marca, sin embargo no hace mención a la titularidad.

A nuestro juicio, si bien son aceptadas las cesiones parciales, en cuanto a los productos, también serán aceptadas las cesiones del $50 \%$ del título, dando lugar ello a una cotitularidad, posterior a la solicitud del registro de marca.

Al parecer, el texto legal consagra además el principio de la libre cesión ya que no destina ningún artículo a obligar la cesión de la marca conjuntamente con la empresa pero si da la posibilidad de que se solicite la cancelación cuando el traspaso induzca al público a error, se tipifique alguna de las prohibiciones al registro o se violen derechos de terceros.

Como novedad en el procedimiento de anotación de las modificaciones de derecho, la Oficina Cubana de la Propiedad Industrial dicta Resolución de anotación sólo en las solicitudes de traspasos y fusiones. Con lo cual la anotación de un cambio de nombre y/o dirección debe ser comprobada por el solicitante con su publicación en el Boletín Oficial.

\section{Licencias de uso}

El Contrato de Licencia de Uso es un contrato muy controvertido, dentro de aquellos que transfieren tecnología.

En un principio, el contrato de licencia de marca fue calificado por la doctrina 
como un contrato legislativamente atípico ${ }^{20}$ y luego el criterio evolucionó teniendo en cuenta que había adquirido una tipicidad social.

Las licencias de marcas pueden ser exclusivas, no exclusivas, únicas o completas, existiendo además una clasificación que va dirigida a los productos o servicios y al territorio que cubre, al amparo de las cuales pueden considerarse total o global y parcial.

El texto legal cubano establece que, salvo pacto en contrario, se consideran no exclusivas.

En cuanto a la Licencia de Uso Exclusiva, teniendo el licenciante la obligación de no otorgar licencias a terceros en ese territorio, el profesor FERNÁNDEZ NOVOA habla de la Licencia de Uso Exclusiva Reforzada ${ }^{21}$ cuando el licenciante además se obliga a no usar la marca en ese territorio.

El Decreto-Ley 203 establece la obligatoriedad de su anotación para que surta efectos frente a terceros pero no entra a regular cuestiones inherentes al contrato en sí ni a su contenido, como por ejemplo la obligación del control de la calidad del producto licenciado por el licenciante, a nuestro juicio cuestión vital en este tipo de contratos.

Establece expresamente la prohibición de anotación de licencias con efectos perjudiciales a la economía nacional o que sean contrarias a la legalidad.

Se aceptan las licencias parciales y se otorga al licenciatario la posibilidad de ejercer acciones en defensa de la marca siempre que el titular le otorgue su consentimiento, exceptuando el caso de la licencia exclusiva en cuyo caso el licenciatario exclusivo puede ejercitar las acciones previo requerimiento e inacción del titular del registro.

\section{Marcas colectivas}

El texto legal cubano deja definida a la marca colectiva, así como la legitimación activa para ostentar tal derecho.

Como aspecto relevante, establece la posibilidad de traspasar una marca colectiva en las siguientes excepciones: a) fusión de dos o más entidades jurídicas; b) división de una persona jurídica; c) descentralización de la actividad económica que realiza una institución estatal.

\section{Otros signos distintivos}

Quedan regulados en esta propia normativa de referencia los Nombres Comerciales, Emblemas Empresariales, Rótulos de Establecimiento y Lemas Comerciales.

Como cuestiones novedosas instaura la figura del Emblema Empresarial como modalidad de Propiedad Industrial, la cual nunca antes había sido regulada por la

\footnotetext{
${ }^{20}$ FERNÁNDEZ-NOVOA, Derecho de Marcas, op cit. p. 227.

${ }^{21}$ Idem, p. 231.
} 
legislación cubana.

Como ventaja, el Emblema Empresarial permite proteger no solo una denominación como ocurre con el Nombre Comercial sino también un diseño asociado a la denominación lo que supone una ventaja técnica.

El Decreto-Ley 203 inserta la posibilidad de adquirir derechos sobre un Nombre Comercial o un Rótulo de Establecimiento por el uso o el registro.

Asimismo, puede solicitar el registro de un Nombre Comercial una persona natural o jurídica con establecimiento comercial o industrial en Cuba mientras que al amparo del antiguo Decreto-Ley 68 sólo adquirían derecho al uso de un Nombre Comercial los OACE, Empresas, Instituciones y OLPP.

De igual forma sucede que pudieran coexistir dos Rótulos de Establecimiento, uno por el uso y otro por el registro, lo cual enseña una práctica que aunque extendida a nivel internacional, nunca antes se experimentó en Cuba, donde la adquisición del derecho sólo era posible con el registro.

El Rótulo de Establecimiento que en cuanto a solicitantes de registro encontraba en el Decreto-Ley 68 los mismos entes ya enumerados cuando nos referimos al Nombre Comercial, da un vuelco en el Decreto-Ley 203 dando la posibilidad de registro tanto a una persona natural que a una jurídica, nacional o extranjera, siempre que tenga un establecimiento industrial o comercial, real y efectivo en Cuba.

\section{Infracción de derechos}

Desde el punto de vista jurídico, el Decreto-Ley 203 es muy acertado al establecer numerosas acciones por infracción de derechos, pudiendo actuar el titular del derecho no sólo contra el tercero que infrinja el derecho, sino también contra terceros que ejecuten actos que manifiesten la preparación de la infracción.

Esta regulación supone un gran paso de avance legislativo toda vez que el antiguo Decreto-Ley 68 sólo regulaba acciones por uso ilícito que comprendía: prohibición del uso, destrucción de las etiquetas y embargo de los productos.

Las acciones por infracción de derechos se establecerán en vía judicial ante el Tribunal Provincial que corresponda conforme a los términos del proceso ordinario, contando con legitimación activa para ello: a) el titular del derecho, b) el licenciatario (según lo pactado), c) una Asociación, Federación, Sindicato o entidad legitimada por el interesado y d) el fiscal si existe afectación a un interés social o estatal.

Las medidas que pueden disponerse por el tribunal en el proceso de conocimiento de una acción por infracción quedaron establecidas en el artículo 126.1. Asimismo, quedaron establecidos los criterios para el cálculo de la indemnización de perjuicios. 


\section{Medidas provisionales}

Quedan establecidas en cuanto a las medidas provisionales: 1) el momento, 2) tipos y 3) ejecución de éstas.

Así, las medidas provisionales pueden ser solicitadas antes, conjuntamente o con posterioridad a la acción, siendo posible que el Tribunal disponga como medidas provisionales: el cese inmediato de los actos de infracción, el embargo o retención de los productos y la suspensión de la importación o exportación. En cuanto a la ejecución, si se establece antes de la acción debe iniciarse en 20 días desde la ejecución de la medida, de lo contrario queda sin efecto y si es después de la acción, queda sin efecto en virtud de la sentencia que se dicte.

\section{Medidas en frontera}

Por último y de forma muy novedosa, el Decreto-Ley 203 incorpora la regulación de medidas en frontera, dando la posibilidad de solicitar al Tribunal Provincial Popular que corresponda, que ordene a la Aduana la retención cuando se supone la preparación de una importación / exportación que infringe derechos.

Si bien el Decreto-Ley 68 no dedicaba ningún acápite a las medidas en frontera, la ejecución de éstas por la Aduana estaba regulada en la hoy derogada Resolución 21 de 1997 "Normas para la retención de mercancías por infracción de los derechos de Propiedad Intelectual" que establecía un procedimiento mediante el cual la Aduana sólo actuaba a instancia de parte permitiendo la retención por diez días.

En Septiembre del 2001 se promulga la Resolución 25/2001 por el Jefe de la Aduana General de la República, que deroga la Resolución 21/97 y que de forma novedosa establece el procedimiento para la ejecución de retenciones por la aduana como órgano ejecutor, pudiendo la misma actuar a instancia de parte, a instancia de autoridad administrativa o judicial competente o de oficio. Sin embargo, la aduana solo ejecuta medidas en frontera por orden de tribunal competente.

Vale aclarar que en Cuba, instancias administrativas serán la Oficina Cubana de la Propiedad Industrial y el Centro Nacional de Derecho de Autor y la autoridad judicial será siempre un tribunal cubano competente. Por otra parte, la actuación de oficio de la aduana está concebida para aquellos casos de falsificación evidente.

Las indicaciones geográficas en nuestro país están reguladas en un cuerpo normativo especial, el Decreto Ley 228 de 20 de febrero del año 2002. En dicha norma se regulan tanto las indicaciones de procedencia como las denominaciones de origen. La titularidad de las mismas las ostenta el Estado Cubano quien confiere derechos de uso a personas naturales y jurídicas. Cuba es miembro del Arreglo de Lisboa relativo a la Protección de las Denominaciones de Origen y su Registro Internacional desde el 17 de septiembre de 1967.

Nuestro país ostenta importantes y reconocidas denominaciones de origen en productos como el tabaco, las aguas minerales y el ron. 
En materia de signos distintivos Cuba es signataria de los siguientes Tratados Internacionales que se encuentran en vigor:

- Arreglo de Madrid relativo a la represión de las indicaciones de procedencias falsas o engañosas en los productos desde el 1 de enero de 1995.

- Arreglo de Madrid sobre el Registro Internacional de marcas desde el 6 de diciembre de 1989.

- Protocolo al Arreglo de Madrid del Registro Internacional de Marcas desde el 26 de diciembre de 1995.

- Arreglo de Niza sobre la Clasificación Internacional de Productos y Servicios desde el 26 de diciembre de 1995.

- Acuerdo de Viena sobre la Clasificación Internacional de los elementos figurativos de las marcas desde el 18 de julio de 1997.

\section{La Gestión y Comercialización de los Resultados Científico-Tecnicos de las Universidades Cubanas y su Vínculo con el Sector Empresarial}

Las universidades, así como los centros públicos de investigación, disponen de un alto potencial innovador.

Este potencial se manifiesta a través de los tradicionales descubrimientos y conocimientos teóricos básicos, que son transmitidos a la sociedad con la formación de profesionales en sus diferentes formas y niveles y con las publicaciones científicas que elevan el estado del arte como fuente del desarrollo, así como, cada día más, a través de resultados científicos aplicados (productos, nuevos usos, equipos y procedimientos) novedosos y útiles para las economías locales, nacionales e internacionales, que como invenciones técnicas e intelectuales, pueden gozar de protección a través del Sistema de la Propiedad Intelectual (Derecho de Patentes de invenciones o de modelo de utilidad, los secretos empresariales, derechos sobre software, entre otras modalidades).

Así, las universidades y centros de investigación de hoy, generadoras permanentes de conocimientos por sus profesores, investigadores y estudiantes de pregrado y postgrado, responden al llamado de la sociedad de contribuir directamente al desarrollo socioeconómico y a la creación de riquezas y a la necesidad de recuperar gastos de la actividad científica, para financiar nuevas investigaciones.

El sector universitario en todo el mundo ha tenido fuertes transformaciones, con beneficios y riesgos, donde se ha generalizado la convicción de la necesidad de encontrar fuentes de $\mathrm{I}+\mathrm{D}+\mathrm{i}$ y de que un adecuado sistema de protección legal 
de sus innovaciones crea un valioso patrimonio que les asegura interactuar con la industria interesada, nacional o extranjera.

Con ese pensamiento a largo plazo, en los años 60 el Comandante en Jefe, Fidel, planteó como un anhelo que el futuro de nuestra patria tendría que ser necesariamente un futuro de hombres de ciencia, de hombres de pensamiento y señaló "...nuestro país vivirá un día, fundamentalmente de sus producciones intelectuales ..." 22 .

La política educacional trazada por la Revolución desde sus inicios conducía a situar el conocimiento y las investigaciones en función del desarrollo socioeconómico del país. Las experiencias contemporáneas de los países más exitosos en este aspecto muestran que las universidades son actores claves en la consecución de este objetivo.

Con la aprobación de los Lineamientos de la Política Económica y Social del Partido y la Revolución se le confiere una mayor prioridad al avance de la investigación y el desarrollo en el sistema económico del país. En el lineamiento 129 se plantea: Diseñar una política integral de ciencia, tecnología, innovación y medio ambiente que tome en consideración la aceleración de sus procesos de cambio y creciente interrelación a fin de responder a las necesidades del desarrollo de la economía y la sociedad a corto, mediano y largo plazo; orientada a elevar la eficiencia económica, ampliar las exportaciones de alto valor agregado, sustituir importaciones, satisfacer las necesidades de la población e incentivar su participación en la construcción socialista, protegiendo el entorno, el patrimonio y la cultura nacionales.

La necesidad de brindar un enfoque de gestión económica empresarial a la organización del ciclo de investigación, producción y comercialización, se refleja en el lineamiento 132 cuando se indica perfeccionar las condiciones organizativas, jurídicas e institucionales para establecer tipos de organización económica que garanticen la combinación de investigación científica e innovación tecnológica, desarrollo rápido y eficaz de nuevos productos y servicios, su producción eficiente con estándares de calidad apropiados y la gestión comercializadora interna y exportadora, que se revierta en un aporte a la sociedad y en estimular la reproducción del ciclo. Extender estos conceptos a la actividad científica de las universidades.

Sin embargo en el caso de Cuba en esta materia aún no existe una política definida por el Ministerio de Educación Superior, a partir del Sistema Nacional de Propiedad Industrial refrendado legalmente, y por ende se carece de normativas propias de las universidades para definir de forma especial la política de protección de las creaciones intelectuales que se producen en estas instituciones, la manera

\footnotetext{
${ }^{22}$ Ver "Contribución de las Producciones Intelectuales al desarrollo de la economía y de la Sociedad Cubanas". Asamblea Nacional del Poder Popular, Comisión de Educación Cultura, Ciencia, Tecnología y Medio Ambiente. Enero 2006.
} 
de garantizar la obtención de fuentes de financiamiento derivadas de la comercialización de los resultados científicos y los mecanismos que faciliten que los inventores reciban una estimulación económica derivada de la explotación económica de los mismos. No obstante consideramos que nos encontramos en el momento oportuno para dar pasos certeros y sólidos en esta dirección.

La protección legal de las innovaciones requiere de una estrategia comercial que no es propia de las universidades y centros de investigación, por ello han de tener presente que tal protección se pierde para los científicos y las universidades cuando aquellos dan a conocer los resultados de sus investigaciones a través de publicaciones, intercambios científicos y otras formas propias de la academia o cuando realizan la protección sin esa estrategia comercial ante la ausencia de asesoría especializada.

Los científicos tienden a publicar y comunicar sus resultados lo más rápidamente posible porque la publicación significa reconocimiento y prioridad científica, pero el concepto de novedad absoluta que exige la protección por patente implica que las publicaciones previas a la presentación de la solicitud de patente van a impedir la posterior patentabilidad de las reglas divulgadas y entonces esos resultados no patentables difícilmente interesan a la industria.

Existe un conjunto de requerimientos o acciones necesarias para la protección y comercialización de los resultados de las universidades, para lo cual éstas no están preparadas, a saber:

- La definición del momento oportuno de realizar las publicaciones científicas para no perder la novedad de las investigaciones.

- Los proyectos de investigación a realizar por parte de las universidades en vínculos con empresas u otros centros científicos, deben respaldarse legalmente a través de contratos o convenios, todo ello para proteger los derechos que puedan derivarse de los resultados de dichos proyectos y para definir de forma correcta quién ostentará la titularidad de dichas creaciones científicas.

- Recibir el asesoramiento especializado para definir las vías de protección de los resultados: patente, secreto empresarial, vínculo de ambas, publicación o revelación de los resultados sino se aspira a obtener derechos exclusivos sobre ellos.

- Definir las formas adecuadas para vincularse con las empresas nacionales y extranjeras para la producción y comercialización de los resultados, definición de los tipos de contratos a utilizar y la determinación acertada de las cláusulas, de forma particular la concesión de exclusividades cuando es procedente. Determinar cuándo son convenientes las asociaciones conjuntas y los aportes por derechos de Propiedad Industrial. 
- Diseñar una correcta estrategia de comercialización de los resultados.

- El control que debe existir de los registros necesarios y las licencias que estipulan las legislaciones de los diferentes países para la adquisición de los derechos, la producción y la comercialización de los resultados.

- El control del cumplimiento de las obligaciones contractuales pactadas.

- Contar con mecanismos que garanticen la permanencia de los derechos exclusivos adquiridos en las diferentes modalidades: marcas, patentes. De acuerdo a la estrategia de comercialización a adoptar, definir cuándo es procedente el abandono, o la renuncia de los derechos adquiridos, o no realizar las prórrogas o renovaciones estipuladas para las diferentes modalidades.

- Consultar la información de patentes y realizar las búsquedas de otras modalidades de la Propiedad Industrial, incluso antes de iniciar las investigaciones científicas.

- Tener un sistema de vigilancia tecnológica, que permita darle seguimiento a los derechos adquiridos en los diferentes países, para evitar las violaciones de éstos por terceros y otros propósitos.

\section{El vínculo universidad - empresa en las universidades cubanas}

Los diferentes objetivos y finalidades de las universidades y del sector productivo, complejizan el proceso de la explotación de los resultados científicos de las universidades y centros de investigación y en particular se torna riesgoso para los creadores cuando el vínculo se plantea directamente entre la universidad y la empresa. Por ello desde hace décadas se ha planteado con tal fin la necesidad de la creación en las universidades y centros de investigación de instituciones de gestión, con sentido empresarial, surgiendo los más diversos sistemas de organización de esta actividad en todo el mundo.

Estas han utilizado formas diferentes de organización para la transferencia de tecnología, entre las que se destacan la creación de oficinas internas universitarias; fundaciones surgidas en el seno de las propias universidades y organizaciones externas con las que las universidades tienen establecidos convenios.

En el caso de Cuba la forma que se ha utilizado es la creación de las Oficinas de Transferencia de Resultados de Investigación (OTRI) en las universidades con un potencial investigativo superior.

La OTRI es el interlocutor de las universidades en sus relaciones con la empresa y otros agentes socioeconómicos; tiene la misión de dinamizar las relaciones entre el mundo científico universitario y el de las empresas, para el aprovechamiento por éstas de las capacidades de I+D y los resultados de la actividad investigadora 
universitaria. Esta Oficina facilita el contacto del mundo empresarial con los investigadores y expertos y el establecimiento de contratos entre la universidad y la empresa, ayuda a buscar fuentes de financiación pública para los contratos de colaboración, difunde el catálogo de conocimientos y capacidades disponibles en las universidades para ser transferidos a la empresa y tiene como función principal gestionar la Propiedad Intelectual y su explotación por empresas interesadas, a través de la promoción de los productos, servicios y procesos innovadores producidos por las universidades, con la finalidad de fomentar el progreso tecnológico nacional e incluso internacional, así como ayudar en la identificación de demandas específicas de tecnologías.

Las universidades cubanas han tenido una larga experiencia desde el triunfo mismo de la Revolución en el vínculo con la empresa nacional sobre todo en la formación de profesionales y en la solución de necesidades concretas de la producción, resultados transferidos y generalizados entre otras formas mediante el movimiento de innovadores y racionalizadores y de los forum de ciencia y técnica ${ }^{23}$. La experiencia descentralizada de la comercialización de sus resultados científicos como patrimonio universitario, protegidos o no legalmente, data de años más recientes.

En la década de los 90 para fortalecer esta actividad de transferencia, sobre todo hacia la industria extranjera ante las nuevas exigencias del período especial para el país y para las universidades de ingresar en divisas, se desarrollan diversas experiencias de interfaces en varias universidades, como en el Instituto Superior Politécnico José Antonio Echeverría con el Centro de Estudios Avanzados (CETA); la Oficina de Transferencia de Resultados de la Investigación (OTRI) de la Universidad de La Habana y la Oficina de Cooperación Universidad-Empresa del Ministerio de Educación Superior en el Instituto Minero Metalúrgico de Moa, entre otras estructuras éstas de impulso, asesoría e interlocutoras con la empresa, pero sin personalidad independiente de la universidad, adscriptas a sus vicerrectorías de investigación fundamentalmente. En general las universidades se han relacionado directamente con la industria nacional y con la industria extranjera,

\footnotetext{
${ }^{23} \mathrm{~A}$ partir del año 1976 con la creación del Ministerio de Educación Superior se consolida todo el sistema de centros universitarios a lo largo y ancho de todo el país, a través del surgimiento de la Red Nacional de Centros de Educación Superior. Se comienza a aplicar los Planes de Estudio Integrados con los diferentes organismos nacionales y la investigación sobre la utilización de egresados. Dando un salto cualitativo en la utilización de la ciencia y la técnica en función del desarrollo social y económico del país se implanta la planificación y dirección de la actividad de I+D en el Ministerio de Educación Superior. Ya en el año 1986 se conforma el Sistema Nacional de Ciencia y Técnica y la instauración de los Programas de Ciencia y Técnica Nacionales, Ramales y Territoriales, los que contemplaban el ciclo completo, es decir desde la investigación hasta la introducción del resultado en la producción. Se da inicio a la descentralización del sistema, dando a los CES la posibilidad de establecer convenios de investigación con las empresas, organizaciones y entidades de los territorios en los que están enclavados. En esta etapa los servicios científico-técnicos, investigaciones contratadas con empresas, etc.; eran presupuestadas, incluyendo los gastos en MLC Cfr. Investigación del MES.
} 
sin tener toda la preparación necesaria para ello y en las últimas décadas han sido asesoradas y representadas por empresas externas a ellas, como es el caso de MERCADU S.A. del Ministerio de la Educación Superior, otras empresas con capacidad exportadora de otros sistemas empresariales y hoy día a través del Centro Internacional de La Habana CIH. S.A. del Ministerio de la Educación Superior.

Las siguientes limitaciones han sido identificadas para accionar sobre ellas y lograr un salto cualitativo en la incidencia de los resultados científicos de la UH en la sociedad y economía del país:

- Falta de una identidad organizativa única para la actividad I+D+i de la UH que permita su identificación por parte de los decisores y actores externos.

- Ausencia de una estructura empresarial dinámica efectiva que represente los intereses y necesidades de la universidad ante el resto del sistema empresarial e instituciones del país.

- Deterioro de la infraestructura instrumental y civil.

- Insuficiente cultura de gestión de la Propiedad Intelectual.

- No existe la autonomía económico financiera necesaria para el desarrollo de la $\mathrm{I}+\mathrm{D}+\mathrm{i}$.

- No existe la compensación monetaria para el personal vinculado a la $\mathrm{I}+\mathrm{d}+\mathrm{i}$ en correspondencia con el impacto económico de los resultados.

- Falta de capacidad ingeniera para el desarrollo de proyectos tecnológicos.

- Insuficiencia de los marcos legales para la interrelación contractual entre los proyectos de $\mathrm{I}+\mathrm{D}+\mathrm{I}$ de la $\mathrm{UH}$ y el resto de las entidades empresariales y científicas del país.

\section{Propuesta de perfeccionamiento}

Los retos actuales imponen la necesidad de definir los principios generales para establecer la política de protección, gestión y comercialización de las creaciones tecnológicas en las universidades cubanas. A continuación nuestras consideraciones en este sentido:

1. Toda acción de investigación que se realice de forma conjunta por facultades y centros de investigación de las universidades con entidades cubanas o extranjeras, debe estar precedida de la negociación y firma de contratos de colaboración o investigación científica en el que se incluyan como elementos básicos los siguientes: 
- Aportes de cada una de las partes al proceso de investigación: financiera, humano, equipos, tecnologías y demás. Destacar si son investigaciones por encargo.

- Obligaciones fundamentales de cada una de las partes.

- Forma de protección de los logros obtenidos.

- Protección de las creaciones preexistentes.

- Titularidad de las creaciones obtenidas. Derechos fundamentales de las partes.

- Confidencialidad de los resultados.

2. Evaluar a nivel de un grupo negociador de la estructura interna de las universidades creadas para estos fines y no a título individual de los investigadores, toda vez que son invenciones laborales, la forma de proteger los resultados científicos y la estrategia a adoptar:

- Patente.

- Diseño industrial

- Secreto empresarial.

- Derecho de Autor en el caso del software.

- Marcas en el caso de productos y servicios a comercializar.

- Formas conjuntas: patente y secreto.

- Difusión de los resultados obtenidos.

La forma de protección a emplear debe estar en consonancia con la estrategia de comercialización de los resultados que incluye: análisis de la competencia, recursos monetarios para enfrentar la solicitud, concesión y mantenimientos de los derechos intelectuales adquiridos, vigilancia tecnológica, cómo enfrentar los litigios derivados de los incumplimientos, entre otros elementos.

3. En el caso de utilizar una vía de protección en materia de Propiedad Industrial, de forma especial evaluar:

- Territorios en los cuales es procedente realizar la protección.

- Evaluar vigencia de los derechos.

- Evaluar en caso de necesidad la renuncia de los derechos.

- Estudio de las leyes de Propiedad Industrial en los lugares donde pretendamos proteger nuestros derechos para evaluar exigencias requeridas.

- Momento de renovar los derechos marcarios. 
- Exigencias definidas en las legislaciones de los diferentes países para que no caduquen los derechos: explotación de las creaciones, vigencia de los derechos, pago de las tasas requeridas.

- Conocimiento de los registros exigidos, entre ellos fitosanitarios, licencias medioambientales para lograr la explotación y comercialización de las creaciones obtenidas.

4. Todas las creaciones obtenidas por profesores e investigadores como resultado del trabajo realizado en las universidades se consideran laborales y por ende la titularidad corresponde a las universidades.

5. Ningún investigador o profesor de las universidades podrá ser titular de un derecho de Propiedad Industrial en el extranjero, como resultado de investigaciones conjuntas realizadas entre universidades cubanas y extranjeras; la titularidad del derecho deberá quedar definido en el contrato de investigación suscrito de forma preliminar.

6. Cada centro de investigación o facultad en la que se generen de forma significativa creaciones intelectuales susceptibles de protección por la vía de la PI deberá tener definido en representante legal ante la Oficina Cubana de Propiedad Industrial (OCPI) para todo lo relacionado con la solicitud y tramitación de los derechos, el que deberá ser designado por resolución del Jefe del centro o Decano de la Facultad. Pueden contratarse los servicios de bufetes especializados (Agentes de Propiedad Industrial).

7. Cada Universidad, en dependencia de su nivel innovativo, deberá tener una interface en sus vínculos con el ámbito empresarial, comúnmente las OTRIS (Oficinas de Transferencia de los resultados de la investigación científica). Deberá quedar establecido la estructura organizativa y funciones de estas oficinas encargadas fundamentalmente de garantizar la debida gestión de la protección y comercialización de los resultados científicos de las universidades.

8. Se deberá estimular la aplicación de las investigaciones realizadas en las universidades y su comercialización, previamente en la economía nacional.

9. Como principios básicos para la transferencia de la tecnología, titularidad de las universidades, se deben evaluar los siguientes elementos:

- Evaluar la vía idónea a utilizar.

- Ser flexible en la forma contractual a emplear y que se atempere a las intenciones objeto del negocio a regular. 
- Previo a cada contrato pactar acuerdos de confidencialidad, independientemente de que sean cláusulas que son objeto de los contratos de transferencia de tecnología.

- Evaluar el crédito y solvencia de la contraparte en el negocio.

- Evaluar las posibilidades reales del éxito del negocio y los frutos del mismo.

- De forma especial pactar cláusulas de propiedad Industrial, a partir de que de estos contratos pueden derivarse creaciones susceptibles de ser protegidas por la vía de la Propiedad Industrial.

- Evaluar la conveniencia de pactar exclusividades en este tipo de contratos.

- Definir la valoración del intangible objeto de transferencia.

- Definir con claridad la forma de realizar los pagos por concepto de la tecnología transferida y sus diferentes modalidades, según las necesidades del negocio.

- Definir con claridad en qué parte recae la obligación de realizar los registros exigidos por las legislaciones foráneas y sus gastos.

- Definir claramente el proceso de reclamaciones ante los incumplimientos y el órgano facultado para dirimir la controversia, en caso de que no exista acuerdo previo entre las partes para solucionar la discrepancia.

- Tener en cuenta el objeto social de las universidades para definir los contratos que pueden ser concertados de forma directa por estas instituciones, o por otra entidad que los represente.

- Evaluar el objeto social y personalidad jurídica de las entidades con las que se debe concertar el contrato para determinar su procedencia.

- Evaluar por la importancia, carácter y trascendencia de estos contratos los que deben ser firmados por la máxima autoridad, o sea el representante legal de la organización, o los que puede ser delegada su firma a otra persona debidamente facultada para ello.

- No iniciar ninguna relación económica, sin que medie una relación contractual previamente concertada conforme a los requisitos legales instituidos.

- Estimular la firma de contratos de cooperación con las entidades de la economía nacional, entre los que pueden contemplarse los de producción cooperada. 
- Evaluar de forma minuciosa los casos en los cuales la tecnología propiedad de las universidades puede ser considerada aporte de capital para el establecimiento de negocios conjuntos en el extranjero o en Cuba. Definir con claridad las cláusulas de estos contratos, a los efectos de preservar los intereses del Estado y los propios de las universidades.

- Evaluar y analizar los resultados y beneficios obtenidos, a partir de la debida protección, vigilancia y comercialización de los derechos intelectuales de las universidades.

- Evaluar ingresos dejados de percibir y daños al patrimonio de las universidades por una incorrecta estrategia de protección y comercialización de sus resultados científicos.

\section{Especial referencia a la Universidad de La Habana}

En junio de 1997, por medio de la Resolución rectoral número 318 surge la Oficina de Transferencia de los Resultados de la Investigación Científica (OTRI).

En el resuelvo Tercero de dicha resolución se establece:

"La tarea principal de la OTRI es gestionar, asesorar y facilitar la introducción de los resultados de la investigación científica de la Universidad de La Habana, protegiéndolos convenientemente y asegurando la obtención de los mayores beneficios."

Actualmente se encuentra en proceso de reorganización y afianzamiento de sus funciones para convertirse en una verdadera unidad que gestiona la ciencia en la $\mathrm{UH}$.

Las funciones fundamentales de la OTRI en la UH son:

1. Establecer vínculos con el sector empresarial para convertir la investigación académica en valor empresarial.

2. Estudiar la viabilidad técnico, comercial, económica y financiera de los proyectos de $\mathrm{I}+\mathrm{D}+\mathrm{I}$ con el apoyo de expertos.

3. Determinación de la estrategia y el control de registro de marcas, patentes y otros derechos de Propiedad Industrial en Cuba y en el extranjero.

4. Facilitar la comercialización a nivel nacional y la exportación de los productos de $\mathrm{I}+\mathrm{D}$.

5. Brindar servicios de consultoría empresarial y capacitación.

Adicionar a lo anterior la Resolución 817 del Ministerio de Economía y Planificación de 11 de diciembre de 2013 que estableció el nuevo objeto social de la $\mathrm{UH}$, que dispone lo siguiente: "Prestar servicios académicos de pregrado, postgrado, 
cursos especializados, inscripción de eventos, consultorías, proyectos, valoraciones, aplicaciones, servicios científicos-técnicos y profesionales, de transferencia de tecnologías y asistencia técnica, así como comercializar los resultados de la ciencia, la técnica e innovación".

De lo anterior se desprende la posibilidad real de la UH de comercializar directamente por diferentes vías los productos derivados de la actividad científica y los derechos de Propiedad Industrial.

\section{Diagnóstico actual de la Propiedad Industrial en la Universidad de La Habana}

- Los proyectos de $\mathrm{I}+\mathrm{D}+\mathrm{i}$ no se respaldan legalmente, en todos los supuestos necesarios, a través de convenios y contratos.

- No se hace uso debido de la información de patentes como fuente tecnológica para la investigación y comercialización de los resultados científicos.

- No se definen adecuadamente las estrategias para proteger los resultados investigativos en Cuba y el extranjero.

- No se realizan las publicaciones científicas en el momento oportuno.

- Presentación de solicitudes de patentes en el extranjero por parte de nuestros investigadores, sin un análisis previo de posibilidades reales y perspectivas.

- Falta de planificación y ausencia de financiamiento para el registro de la Propiedad Industrial en Cuba y otros territorios de interés.

- Insuficiente explotación económica de las patentes.

- En ocasiones caducan las patentes, marcas y demás modalidades de la propiedad industrial concedidas titularidad de la UH, por falta de control y vigilancia de nuestros derechos.

- Falta de una acertada negociación de productos y transferencia tecnológica.

- Evaluación incorrecta de los bienes intangibles.

- Aún son bajos los ingresos por ventas de productos que incorporan derechos de Propiedad Industrial y otras modalidades de transferencia tecnológica. 
Estos análisis realizados no son privativos de las universidades sino que aún en nuestro sistema empresarial tanto por razones de incultura en materia de Propiedad Industrial, como por falta de una debida gestión de nuestros derechos existen estas prácticas incorrectas. Por tal motivo como ya hemos apuntado esta materia es prioridad en todo el proceso de actualización de nuestro modelo económico y social, reflejado en los Lineamientos de la política económica y social del Partido y la Revolución.

\section{Estadísticas Sobre los Derechos de Propiedad Industrial en la Universidad de La Habana}

- 35 patentes concedidas. De ellas, 18 del Instituto de Ciencia y Tecnología de los Materiales (IMRE); 2 del Centro de Estudios de Proteínas de la Facultad de Biología; 10 del Centro de Estudios de Productos naturales (CEPN) de la Facultad de Química; 2 de la Facultad de Química y 3 del Instituto de Farmacias y Alimentos (IFAL).

- De ellas 7 en régimen de cotitularidad con otros centros.

- Existen 2 patentes en estado de solicitud, 1 del IMRE y 1 de la Facultad de Química.

- 24 marcas de registradas. De ellas 14 del IMRE y 10 del Centro de Biomateriales.

- Existe un grupo de productos protegidos por la vía del secreto industrial.

- Existe 1 modelo de utilidad solicitado por el IMRE.

- En el año 2013 caducaron 6 patentes por falta de pago.

A partir del diagnóstico efectuado se ha propuesto el siguiente procedimiento, el cual ya ha comenzado a implementarse:

1. Todo proyecto de investigación científica con otras universidades o centros de investigación tanto nacionales o extranjeras debe respaldarse legalmente a través de contratos de colaboración científica técnica. Dichos contratos serán firmados por la Directora de Ciencia y Técnica de la Universidad de La Habana (UH). Ya se han firmado dos convenios marcos de cooperación científico técnica con el Centro de Inmunología Molecular y con el Centro de Ingeniería Genética y Biotecnología. 
2. Cada vez que se inicie un proyecto de investigación científica deberán solicitarse, a través de la OTRI los servicios de la Oficina Cubana de la Propiedad Industrial (OCPI) para la consulta de la información de patentes.

3. Deberán firmarse contratos de confidencialidad entre la dirección de las facultades o centros y los profesores e investigadores que participen en investigaciones científicas, a los efectos de preservar el valor comercial de la información no divulgada.

4. Cuando sea procedente se deberán firmar acuerdos de confidencialidad entre la UH y otros centros de investigación o universidades para preservar el carácter de información no divulgada de la información transferida.

5. La estrategia para definir la forma de protección más acertada de los resultados de las investigaciones científicas (patente, secreto, modelo de utilidad, marcas) deberá ser sometida a la consideración del grupo negociador de la OTRI integrado por especialistas de diferentes áreas del conocimiento como economistas, juristas, contadores y científicos de diferentes especialidades.

6. Actualización de los representantes legales tanto a nivel de facultades, centros y OTRI para las solicitudes de derechos de Propiedad Industrial ante la OCPI y vigilancia del mantenimiento de los mismos. Definición de las funciones de estos representantes.

7. Deberá planificarse anualmente el financiamiento necesario para los registros y mantenimiento de los derechos de Propiedad Industrial en Cuba y en el extranjero.

8. Toda propuesta de negocio para comercializar productos resultados de la ciencia universitaria, transferir derechos de Propiedad Industrial, o brindar servicios científico técnicos o asistencia técnica deberá ser tramitada por las facultades y centros a través de la OTRI, quien la someterá a la evaluación del grupo negociador y a la dirección jurídica de la UH. El rector determinará quién deberá ser la persona facultada para la firma de estos contratos, según alcance, importancia y complejidad del negocio.

9. Los investigadores recibirán una remuneración por la explotación económica de los resultados científicos protegidos a través de patente. El \% de dicha remuneración deberá definirse en la normativa interna que deberá promulgar la UH para organizar la utilización acertada de los derechos de propiedad industrial en el marco universitario. Para ello se requiere que previamente se promulgue el Reglamento del Decreto-Ley 290 sobre invenciones, modelos de utilidad y dibujos y modelos industriales que deberá pronunciarse sobre 
al procedimiento a seguir para garantizar que se cumpla este derecho ya previsto en el Decreto-Ley 290 como analizamos anteriormente.

10. Cada centro o facultad deberá tener definida una estrategia diferenciada para garantizar la explotación económica de las patentes, secretos y otros resultados de la ciencia.

11. Se elaborarán e implementarán programas docentes en materia de Propiedad Industrial a impartirse como asignaturas optativas y electivas en las carreras que lo ameriten, pues solo se imparte como asignatura obligatoria definida en el diseño curricular en la carrera de Derecho.

Para la organización, implementación y control de estas acciones en el orden institucional se creará una oficina de propiedad intelectual subordinada a la OTR e integrada por varios especialistas en esta materia.

En el orden normativo se dictará en breve una resolución rectoral en la UH que reglamente todo este proceso y las obligaciones de las facultades, centros, OTRI e investigadores y profesores en esta materia, así como el control efectivo de estas acciones.

En especial el estatuto interno de Propiedad Industrial incluirá entre otros elementos:

1. Creación de la oficina de Propiedad Intelectual. Funciones y subordinación.

2. Convenios de colaboración científico técnica con centros de investigación científica y universidades tanto nacionales como extranjeras. Contratos $\mathrm{i}+\mathrm{d}+\mathrm{i}$. Procedimiento para la elaboración y firma de los mismos.

3. Titularidad de las creaciones.

4. Deberes y derechos de los investigadores.

5. Acuerdos de cotitularidad con centros de investigación y universidades.

6. Uso de la información de patentes.

7. Publicaciones científicas.

8. Acuerdos de confidencialidad.

9. Contratos para comercializar los productos protegidos por la vía de la propiedad industrial y otras formas de transferencia de tecnología. Procedimiento.

10. Planificación de los fondos para trámites de registros de los derechos de propiedad industrial en Cuba y en el extranjero. 
11. Destino de los fondos derivados de la explotación económica de los derechos de propiedad industrial. Remuneración a los investigadores.

\section{Conclusiones}

Elementos importantes fundamentan la prioridad que en los momentos actuales se le concede en Cuba al reconocimiento de la propiedad industrial. Entre ellos se destacan la suscripción de importantes convenios internacionales, en especial el Acuerdo ADPIC de la OMC, la aprobación de políticas encaminadas a poner esta institución al servicio del desarrollo científico, tecnológico, industrial y comercial de nuestro país, incluido el proceso inversionista tanto nacional como extranjero y la aprobación de nuevas normativas atemperadas a nuestro intereses sociales y a la práctica y doctrina internacional.

No obstante aún subsisten insuficiencias asociadas a la falta de cultura en esta materia y a una indebida gestión de los activos intangibles como parte del patrimonio empresarial, lo cual conduce en ocasiones a no valorar, proteger, comercializar y defender acertadamente los derechos de propiedad industrial.

En el orden normativo, se requieren nuevas disposiciones legales o el perfeccionamiento de las existentes en áreas como la información no divulgada, la represión de la competencia desleal, el control del proceso de transferencia tecnológica y la observancia de los derechos intelectuales tanto en el orden administrativo, civil, mercantil y penal.

A partir de las transformaciones actuales del modelo económico y social en Cuba, las universidades cubanas tienen el reto de poner al servicio de la economía sus investigaciones científicas. Asimismo deben garantizar el financiamiento necesario para fomentar el desarrollo de la ciencia aplicada y contribuir a estimular a los creadores e investigadores, protagonistas por excelencia de las creaciones intelectuales.

Para ello se requiere en primer término la realización de investigaciones científicas en función de las principales demandas del sector empresarial, sin obviar por supuesto el desarrollo de investigaciones básicas. Unido a ello se necesita una correcta política y reglamentación de la protección y gestión de las creaciones científicas y su comercialización acertada a partir de los diferentes mecanismos existentes.

Lo anterior no es posible sin una capacitación y especialización del personal vinculado a estas tareas, incluido por supuesto a los investigadores, sin la existencia de interfaces que tributen de forma coherente a garantizar los objetivos anteriormente descritos y sin la existencia de normativas internas especializadas que fundamenten legalmente la institucionalidad y el procedimiento a seguir para la debida protección y comercialización de las creaciones científicas universitarias. 


\section{Referencias}

Baylos Corroza, Hermenegildo, Tratado de Derecho Industrial Propiedad Industrial Propiedad Intelectual Derecho de la Competencia Económica Disciplina de la Competencia Desleal, Editorial Civitas, S.A., Madrid 1978

Bercovitz Rodriguez-Cano, Alberto; "Apuntes de Derecho Mercantil", tercera edición (revisada y puesta al día), Editorial Arazandi, 2002.

Fernández - Novoa, Derecho de Marcas, Madrid, 1990.

Gómez Segade, José Antonio, "La Ley de Patentes y Modelos de Utilidad", Editorial Civitas, S.A., 1988.

McCarthy, J. Thomas, "McCarthy 's Desk Encyclopedia of Intellectual Property", Second Edition, The Bureau of National Affaires, Inc, Washington, D.C.

Normas Jurídicas, Antecedentes históricos y legislativos. www.ocpi.cu/normasjurídicas.htm

P.C. Breuer Moreno, "Tratado de patentes de invención", Vol.I, Buenos Aires, 1957.

P. Devant, R. Plasseraud, R. Gutmann, H. Jacquelin, M. Lemoine; "Les Brevets D’Invention", Paris, Libraire Dalloz, 11, rue Soufflot, Ve, 1971.

Roffe Pedro, "Evolución e importancia del sistema de la propiedad intelectual", Comercio Exterior, Vol. 37, núm 12, México, diciembre de 1987.

Tato Plaza, Derecho Español de Marcas, Magíster Lvcentinvs, 1998.

LEGISLACION.

Decreto-Ley 68 de 14 de mayo de 1983, Artículo 21, publicado en Gaceta Oficial Extraordinaria, No. 10, La Habana, sábado 14 de mayo de 1983. Año LXXXI.

Decreto Ley 203 de 2 de mayo del 2000, artículo 2, Gaceta Oficial Extraordinaria No. 3 Año XCVIII.

Decreto Ley 290 DE LAS INVENCIONES Y DIBUJOS Y MODELOS INDUSTRIALES Gaceta Oficial Ordinaria de miércoles 1 de febrero de 2012, Número 2, Año CX, página 9.

Decreto Ley 228 DE LAS INDICACIONES GEOGRAFICAS. GOE de 22 de febrero de 2002 Año C, Número 11, página 333.

Decreto Ley 291 DE PROTECCIÓN DE LAS VARIEDADES VEGETALES, Gaceta Oficial Ordinaria de miércoles 1 de febrero de 2012, Número 2, Año CX, página 27.

Decreto Ley 292 DE LOS ESQUEMAS DE TRAZADO DE CIRCUITOS INTEGRADOS, Gaceta Oficial Ordinaria de miércoles 1 de febrero de 2012, Número 2, Año CX, página 36.

Recife, Olinda, Maceió, 2014 